\title{
Afatinib: emerging next-generation tyrosine kinase inhibitor for NSCLC
}

This article was published in the following Dove Press journal:

OncoTargets and Therapy

4 March 2013

Number of times this article has been viewed

\section{Valerie Nelson \\ Jacqueline Ziehr \\ Mark Agulnik \\ Melissa Johnson}

Robert H Lurie Comprehensive Cancer Center of Northwestern University, Chicago, IL, USA
Correspondence: Melissa Johnson Robert H Lurie Comprehensive Cancer Center of Northwestern University, 676 North St Clair Street, Suite 850, Chicago, IL 606I I, USA

$\mathrm{Tel}+$ I 3126956180

Email melissa-johnson@northwestern.edu
Abstract: The discovery of epidermal growth-factor receptor (EGFR)-activating mutations and the introduction of oral EGFR tyrosine kinase inhibitors (EGFR-TKIs) have expanded the treatment options for patients with non-small cell lung cancer. The first two reversible EGFR-TKIs, erlotinib and gefitinib, are approved for use in the first-line setting in patients with known EGFR-activating mutations and in the second- and third-line settings for all NSCLC patients. These first-generation EGFR-TKIs improve progression-free survival when compared to chemotherapy in patients with EGFR-activating mutations in the first-line setting. However, nearly all patients develop resistance to EGFR-directed agents. There is a need for further therapy options for patients with disease progression after treatment with reversible EGFRTKIs. Afatinib is an irreversible ErbB family blocker that inhibits EGFR, HER2, and HER4. In vitro and in vivo, afatinib have shown increased inhibition of the common EGFR-activating mutations as well as the T790M resistance mutation when compared to erlotinib and gefitinib. Clinically, afatinib has been evaluated in the LUX-Lung series of trials, with improvement in progression-free survival reported in patients with EGFR-activating mutations in both first- and second-/third-line settings when compared to chemotherapy. Further investigation is needed to determine the precise role that afatinib will play in the treatment of patients with non-small cell lung cancer and EGFR-activating mutations.

Keywords: afatinib, EGFR, irreversible EGFR inhibitor, EGPR-TKIs, LUX lung, resistance mutation, targeted therapy

\section{Introduction}

Lung cancer is the leading cause of cancer death globally, with a low 5-year survival rate of $15 \% .{ }^{1}$ Non-small cell lung carcinoma (NSCLC) is the most common type, comprising $85 \%$ of lung cancers. ${ }^{1}$ Risk factors for lung cancer are well described, and include first- and secondhand cigarette smoking, ${ }^{2,3}$ radon gas, ${ }^{4}$ asbestos, ${ }^{5}$ and other airborne chemicals and particulates. ${ }^{1}$ However, among lung cancer patients who have not been exposed to traditional risk factors, a substantial proportion are found to have oncogene-driven malignancies, including patients whose tumors are driven by epidermal growth-factor receptor (EGFR).

The vast majority of NSCLC patients are diagnosed at advanced stages, at which point locoregional therapy is not an option. ${ }^{1}$ Until recently, cytotoxic chemotherapy administered intravenously was the only treatment option for these patients, with unsatisfactory median overall survival rates in the 12 -month range. ${ }^{6}$ With the discovery of EGFR mutations, and subsequent introduction of oral EGFR tyrosine kinase inhibitors (EGFR-TKIs), the therapeutic options have expanded for NSCLC patients. 


\section{Epidermal growth factor receptor- activating mutations}

The EGFR family of cell surface-receptor tyrosine kinases controls the intracellular signaling pathways that promote cell growth, proliferation, differentiation, and migration. ${ }^{7}$ Members of the ErbB family include EGFR (HER1/ErbB1), HER2 (ErbB2), HER3 (ErbB3), and HER4 (ErbB4). These cell-membrane receptors are composed of an extracellular domain containing a ligand-binding pocket and an intracellular catalytic domain. ${ }^{8}$ Binding of extracellular growth-factor ligands causes dimerization of the receptors, leading to homo- or heterodimers. ${ }^{9}$ Formation of these dimers activates the receptors' tyrosine kinase activity, initiating intracellular signaling cascades.

Lung adenocarcinoma with activating EGFR mutations is now a well-described molecular subgroup of lung adenocarcinoma. Multiple aberrations in the signal-transduction pathways controlled by EGFR have been implicated in NSCLC. For example, mutations in genes encoding EGFR pathway proteins result in dysregulation of the proteins' tyrosine kinase activity and lead to proliferation, survival, and dissemination of malignant cells. ${ }^{10,11}$ Elevated gene copy number and increased expression of the receptor proteins have also been described. ${ }^{11}$

Multiple specific EGFR-activating mutations have been identified, including short in-frame single nucleotide mutations, in-frame duplications/insertions, and singlenucleotide substitutions, all surrounding the adenosine triphosphate (ATP)-binding pocket. ${ }^{12}$ The most common EGFR mutations in patients with lung adenocarcinoma are deletions in exon 19 (the LREA deletion) and a single amino acid substitution in exon 21 - L858R. These mutations are located within the catalytic domain and result in constitutive EGFR activation (Figure 1). ${ }^{8}$ Exon 19 deletion and exon $21 \mathrm{~L} 858 \mathrm{R}$ mutation account for $10 \%-15 \%$ of Caucasian patients and $50 \%$ of Asian patients with NSCLC. Less common mutations include L861Q in exon 21 and G719X in exon $18 .{ }^{13}$ While EGFR-activating mutations occur at a higher prevalence in certain populations, such as females, never-smokers, and Asians, clinical characteristics alone cannot be used to predict EGFR status, and National Comprehensive Cancer Network (NCCN) guidelines recommend mutational analysis of tumor tissue to verify the presence of EGFR mutations prior to initiating EGFR-directed therapy. Roughly 20,000 patients in the United States are diagnosed with lung adenocarcinoma with activating EGFR mutations yearly.

\section{The era of EGFR-TKIs}

There is evidence that tumors with EGFR-activating mutations become completely dependent on EGFR to activate downstream intracellular signaling cascades. When inhibited

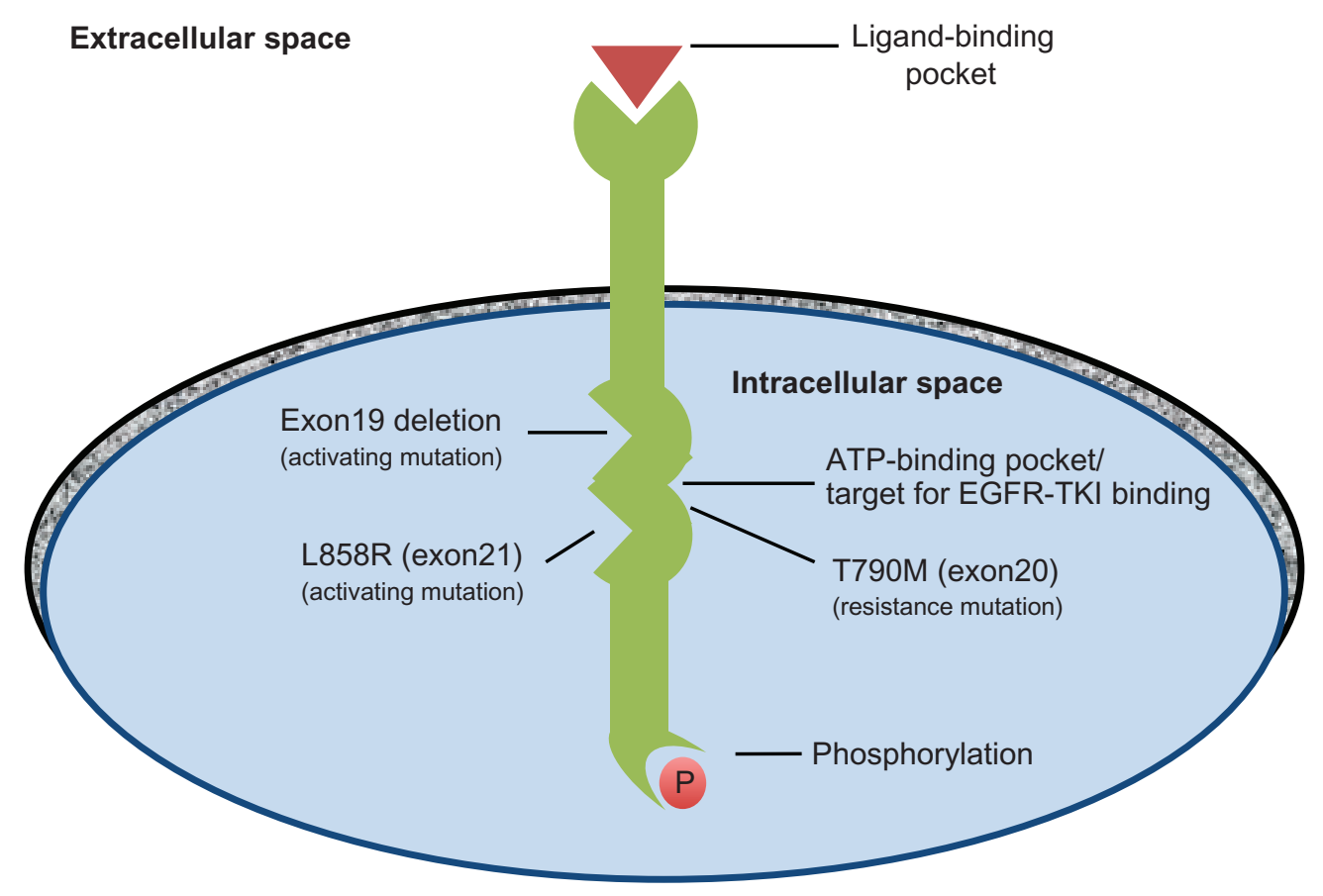

Figure I The EGFR receptor and locations of activating and resistance mutations.

Abbreviations: EGFR, epidermal growth-factor receptor; ATP, adenosine triphosphate; TKI, tyrosine kinase inhibitor. 
by EGFR-TKIs, the tumor cells are unable to replicate and undergo apoptosis. ${ }^{14}$ TKIs compete with ATP at the receptor intracellular catalytic domain, thus preventing ATP binding, autophosphorylation, and downstream intracellular signaling. ${ }^{9,15}$ Erlotinib and gefitinib, the first-generation EGFR-TKIs, bind reversibly to the kinase domain and effectively inhibit both wild-type and mutated EGFR. ${ }^{13}$

Initial FDA approval for erlotinib in 2004 was based on the results of the BR21 trial, a phase III international, randomized, double-blind, placebo-controlled trial comparing erlotinib $150 \mathrm{mg}$ daily plus best supportive care (BSC) with BSC alone in second- and third-line settings in 731 unselected patients with stage IIIB or IV NSCLC and Eastern Cooperative Oncology Group performance status of 0-3. ${ }^{16}$ The response rate (RR) to erlotinib was $9 \%$ versus $1 \%$ for placebo $(P<0.001)$. Progression-free survival (PFS) was longer in the erlotinib group, at 2.2 months versus 1.8 months for placebo $(P<0.001)$. Note that EGFR mutation testing was not part of this trial.

As the biology of EGFR-activating mutations was better clarified, first-generation EGFR-TKIs were tested specifically in patients with EGFR-activating mutations. Tumors with activating EGFR mutations were found to have unique sensitivity to targeted therapy with EGFR-TKIs, ${ }^{17,18}$ with RRs around $75 \%$ in the first-line setting, ${ }^{19,20}$ a vast improvement over the $9 \%$ seen in unselected populations. Some data suggest that patients with EGFR exon 19 deletions are more susceptible to the activity of reversible EGFR-TKIs compared to those with the exon 21 L858R mutation. ${ }^{18,21}$

Further studies then compared first-generation EGFRTKIs (erlotinib and gefitinib) to chemotherapy in patients with EGFR-activating mutations in advanced NSCLC. In the first-line setting, a European randomized trial, EURTAC, compared erlotinib $150 \mathrm{mg}$ daily to platinum-containing chemotherapy regimens (cisplatin or carboplatin with docetaxel or gemcitabine) in 174 patients with advanced NSCLC. PFS was 9.7 months in the erlotinib group versus 5.2 months in the chemotherapy group. There was no difference in overall survival (OS). There were fewer adverse events in patients treated with erlotinib. ${ }^{22}$ Similar results were reported in an analogous trial in Chinese patients - OPTIMAL. ${ }^{23}$ Based on these studies, the NCCN guidelines were amended in 2011 to recommend erlotinib for first-line use in patients with documented EGFR mutations.

Gefitinib is approved in the European Union for use in advanced-stage EGFR-mutated NSCLC. ${ }^{24}$ Its approval is based on demonstrated improved PFS when compared to chemotherapy in the first-line setting for Asian patients with
EGFR mutations in three phase III randomized controlled trials (IPASS, NEJ002, and WJTPG3405). ${ }^{25-27}$ While gefitinib is not approved in the United States, the NCCN guidelines comment that "in areas of the world where gefitinib is available, it may be used in place of erlotinib."1

At the present time, erlotinib and gefitinib are used in the first-line treatment of patients with advanced NSCLC and EGFR-activating mutations. Erlotinib and gefitinib can also be used in second- and third-line settings in unselected patients, regardless of EGFR mutation status. ${ }^{1}$ While RR and PFS in the EGFR-mutated population favors the use of EGFR-TKIs as compared to chemotherapy in the first-line setting, disease progression typically occurs after a median of 10-14 months on an EGFR-TKI. ${ }^{25,28}$ Once progression occurs, further treatment options are limited, particularly for patients with moderate to poor performance status who will be unable to tolerate toxicities from cytotoxic chemotherapy. Thus, there is a need for therapy options after progression on first-generation anti-EGFR agents.

\section{Resistance to first-generation EGFR-TKIs}

Nearly all EGFR-mutated patients eventually develop resistance to reversible EGFR-TKIs after a median of 14 months. ${ }^{28}$ In clinical practice, it is not always feasible to obtain tissue sampling with EGFR testing at the time of progression. For these reasons, Jackman et $\mathrm{al}^{29}$ proposed criteria to define acquired resistance that have been used in multiple clinical studies.

The Jackman criteria are as follows: patients who have a tumor known to harbor an EGFR-activating mutation (such as exon 19 deletion or exon 21 L858R mutation, amongst others), or show objective clinical benefit from treatment with EGFR-TKI as defined by objective response or durable stable disease ( $>6$ months), and then have systemic progression of disease while on continuous treatment with EGFR-TKI should be considered to have acquired resistance. These criteria have been noted to have a positive predictive value of $66 \%$ for EGFR-sensitizing mutations. ${ }^{29}$

There are multiple known mechanisms of resistance to first-generation EGFR-TKIs. Most mechanisms are thought to be secondary (acquired). The most common secondary resistance mutation is the $\mathrm{T} 790 \mathrm{M}$ missense mutation in exon 20 , which accounts for $50 \%-60 \%$ of patients with disease progression while on a first-generation EGFR-TKI. ${ }^{30-32}$ The T790M mutation is referred to as the gatekeeper mutation, as it occurs within the ATP-binding site in a similar location to known resistance mutations in other tyrosine kinases (Figure 1). ${ }^{8,14}$ It is hypothesized to interfere with 
first-generation EGFR-TKI binding by steric hindrance; the T790M mutation produces a bulky methionine side chain in the receptor kinase domain. ${ }^{33}$ Besides T790M, other secondary resistance mutations include D761Y in exon $19,{ }^{34} \mathrm{~T} 854 \mathrm{~A}$ in exon $21,{ }^{35}$ and L747S in exon $19 .{ }^{36}$

An additional mechanism of resistance is amplification of MET tyrosine kinase, which can occur in up to $22 \%$ of patients and can coexist with or be independent of EGFR T790M. ${ }^{37}$ Less common resistance mechanisms include histologic transformation to a small-cell carcinoma, occurring in up to $14 \%$ of patients resistant to EGFR-TKIs, ${ }^{31,32}$ and morphologic changes consistent with an epithelialmesenchymal transition, the therapeutic implications of which are unknown. ${ }^{38}$

There are also reports of primary resistance genotypes, including T790M missense mutation, in a small subset of patients. ${ }^{39}$ It has been hypothesized that low levels of T790M in the presence of common activating mutations might reduce effectiveness of reversible EGFR-TKIs in first-line treatment. ${ }^{39-41}$ Indeed, up to $20 \%-30 \%$ of EGFR-mutated patients do not respond to first-generation EGFR-TKIs. ${ }^{18,25}$

\section{Attempts to overcome resistance}

Currently, there is no standard option for advanced NSCLC patients who experience progression after treatment with a reversible EGFR-TKI, and patients who are candidates for further therapy are typically treated with cytotoxic chemotherapy or enrolled in clinical trials investigating novel agents for acquired resistance. Some have advocated continuing an EGFR-TKI, either the same medication or switching to the other first-generation option; ${ }^{42-44}$ however, there is no consensus surrounding this practice. The rationale for continuing a first-generation TKI is that many tumors remain addicted at least in part to the EGFR signaling pathway despite acquired resistance. ${ }^{42}$ Riely et $\mathrm{al}^{42}$ demonstrated decreased positron emission tomography avidity and tumor size with reintroduction of an EGFR-TKI even after progression on an EGFR-TKI.

Many drugs have been studied in patients who progressed after treatment with a reversible EGFR-TKI, including XL-647, ${ }^{45}$ dasatinib, ${ }^{46}$ and neratinib,${ }^{47}$ with little success. Combinations of therapy such as cetuximab plus erlotinib ${ }^{48}$ and gefitinib plus everolimus ${ }^{42}$ have also been tried. The most promising drug thus far has been afatinib (BIBW2992; Boehringer-Ingelheim Pharma, Ingelheim, Germany), ${ }^{49,50}$ an ErbB family blocker with reported in vitro and in vivo activity against EGFR mutant tumors harboring exon 19 deletions, exon 21 L858R mutations and the exon 20 T790M "resistance" mutations.

\section{Pharmacology}

Afatinib is a highly selective, irreversible inhibitor of EGFR, ErbB2/HER2, and ErbB4/HER4. ${ }^{49}$ Like gefitinib and erlotinib, afatinib is an aniline-quinazoline derivative. ${ }^{50}$ Afatinib covalently binds directly to the ATP-binding site in the kinase domains of both EGFR (Cys 773) and HER2 (Cys 805). ${ }^{49}$ The irreversible, covalent binding of afatinib leads to longer suppression of receptor kinase activity than with reversible first-generation EGFR-TKIs, as the kinase activity is suppressed until the synthesis of new receptors. ${ }^{9}$ Afatinib further improves on the activity of first-generation EGFR-TKIs by its activity against multiple receptors. The irreversible binding of afatinib to HER2 inactivates the preferred dimerization partner of EGFR, preventing the dimer formation that promotes the receptors' tyrosine kinase activity. ${ }^{33,49}$

Afatinib has shown preclinical activity in both first-line and second-line settings. Both in vivo and in vitro models have shown that afatinib has increased affinity for the EGFR L858R mutation compared to the first-generation EGFR-TKIs. ${ }^{51}$ In cell-culture models, acquired resistance may develop at a slower rate when irreversible or secondgeneration EGFR-TKIs such as afatinib are used in the first-line setting. ${ }^{52}$ Additionally, afatinib has higher potency than reversible EGFR-TKIs in reducing survival of NSCLC cell lines with the T790M resistance mutation (Table 1$)^{49}$ and in cell lines with the less common secondary resistance mutation T854A. ${ }^{35}$ Finally, afatinib has shown activity in xenograft models with EGFR L858R/T790M double-mutant murine lung tumor. ${ }^{49}$

The recommended phase II dose of afatinib is $50 \mathrm{mg}$ orally daily based on phase I trials in patients with advanced solid tumor malignancies as well as specifically in patients with advanced NSCLC. ${ }^{50,53,54}$ At $50 \mathrm{mg}$, more than $90 \%$ of patients experienced a treatment-related adverse event, but dose-limiting adverse events were experienced in an acceptable number of patients. ${ }^{50,53}$ Because the severity (but not the overall incidence) of adverse events increases

Table I Inhibition of EGFR cell lines by afatinib compared to erlotinib as shown by $\mathrm{EC}_{50}$ values

\begin{tabular}{llll}
\hline & Wild-type & L858R mutation & L858R + T790M \\
\hline Afatinib & 60 & 0.7 & 99 \\
Erlotinib & 110 & 40 & $>4000$ \\
Gefitinib & 157 & 5 & $>4000$ \\
\hline
\end{tabular}

Notes: Units in $\mathrm{nM}$.

Abbreviations: EGFR, epidermal growth-factor receptor; $\mathrm{EC}_{50}$, half maximal effective concentration.

(C) 2008. Nature Publishing Group. Adapted with permission from Li D, Ambrogio L, Shimamura T, et al. BIBW2992, an irreversible EGFR/HER2 inhibitor highly effective in preclinical lung cancer models. Oncogene. 2008;27(34):4702-47। I. ${ }^{49}$ 
with dose increases from $40 \mathrm{mg}$ daily to $50 \mathrm{mg}$ daily, some phase II trials begin at a starting dose of $40 \mathrm{mg}$ daily. ${ }^{54-56}$

To maximize plasma drug concentrations, afatinib should be taken while fasting. ${ }^{50}$ Maximal plasma concentrations are attained 3-6 hours after drug administration. ${ }^{50,57}$ With oncedaily dosing, afatinib reaches a steady state after 7 days ${ }^{50}$ and has a half-life of 30-40 hours. ${ }^{53}$ Afatinib undergoes minimal metabolism and has no identified major circulating metabolites. It does not require dose adjustment for renal impairment. Unlike erlotinib, there is no detectable cytochrome P450-mediated metabolism of afatinib. ${ }^{58}$

\section{Safety and tolerability}

EGFR is expressed in the epithelium; it helps maintain mucosal integrity and promote mucosal repair in the gut and maintains the protective barrier of the skin. ${ }^{56,57}$ Therefore, the most common treatment-related adverse events of EGFR-TKIs in general, and afatinib in particular, are gastrointestinal (GI) and cutaneous side effects, specifically diarrhea and rash. ${ }^{22,55}$

Almost all patients experience at least one treatmentrelated adverse event when receiving afatinib therapy, with $90 \%$ of patients experiencing either a GI or cutaneous adverse event. ${ }^{50,53,55,57}$ GI side effects include diarrhea (95\%), nausea, vomiting, stomatitis, and decreased appetite. Cutaneous adverse events include rash, acne, dry skin, folliculitis, and palmar-plantar disorders. The rash is usually located on the face and trunk; when severe, it can cause ulceration and desquamation. ${ }^{57}$ In combined data of treatment-related adverse events from recent phase II/III trials, $88 \%$ of patients had diarrhea and $81 \%$ experienced a rash $(\mathrm{n}=489) .{ }^{55,61}$ Of these patients, the majority $(>80 \%)$ had grade 1 or 2 , and none had grade 4 , adverse events. ${ }^{55,61}$ Both GI and cutaneous adverse events are usually manageable with supportive care, dose reduction, or interruption of treatment. ${ }^{50,57,59}$ Afatinib was associated with possible treatment-related interstitial lung disease (4/129 patients) in only one study, ${ }^{55}$ similar to the infrequent reports of interstitial pneumonia, pneumonitis, acute respiratory distress syndrome, pulmonary fibrosis, and alveolitis associated with erlotinib. ${ }^{60}$ In phase II/III trials, afatinib is associated with a dose-reduction rate of $38 \%-67 \%{ }^{55,56,61}$ and a drug-discontinuation rate of $8 \%-20 \% .^{55,62}$

\section{Efficacy studies}

Clinically, afatinib has shown promise in the LUX-Lung series of trials. The complete series of afatinib trials in advanced NSCLC is summarized in Table 2.

LUX-Lung 1 was a phase IIb/III study of 585 patients with stage IIIb or IV NSCLC (adenocarcinoma) who progressed on chemotherapy including at least one platinumbased regimen and at least 12 weeks of erlotinib or gefitinib. ${ }^{61}$ Patients were randomized to afatinib $50 \mathrm{mg}$ /day plus BSC or placebo plus BSC. Patients were treated until disease progression or undue toxicity. While the primary end point of OS was not statistically significant, OS of 10.78 months in the afatinib group versus 11.96 months in the placebo group (hazard ratio [HR] $1.077, P=0.74$ ), there was a statistically significant difference in the secondary end point of PFS in favor of afatinib. Median PFS in the group receiving afatinib was 3.3 months versus 1.1 months for patients who received placebo (HR 0.38, $P<0.0001$ ). Partial RR was $7 \%$ in the afatinib group versus $0.5 \%$ in the placebo group $(P<0.01)$. Disease-control rate was $58 \%$ in the afatinib group versus $19 \%$ in the placebo group $(P<0.0001)$.

There are several potential reasons why LUX-Lung 1 did not show a difference in OS for afatinib. First, the study design was based on the assumption that the control-group OS would be a median of 4.7 months, as observed in the second-line and third-line phase III trial of erlotinib, ${ }^{16}$ but instead OS survival in the placebo group surprisingly exceeded 10 months. This could be attributable to the additional therapies given after progression on the trial. Notably, more patients in the placebo group (79\% versus 68\%) received additional chemotherapy upon progression. In an exploratory analysis of the 191 patients who did not receive subsequent systemic treatment upon progression on this trial, there was a survival advantage for patients who received afatinib over placebo (5.8 vs 4.6 months, HR 0.65).

It is important to note that EGFR mutation status was not required for study entry, and so the number of patients with EGFR mutations is unknown. Less than half of the patients in the study had complete or partial response to previous reversible EGFR-TKI therapy, less than would be expected if they all had EGFR-activating mutations. Indeed, a more robust improvement in PFS was seen in the 96 patients who were known to harbor EGFR-activating mutations. Similarly, when analyzing patients who met Jackman criteria for acquired resistance, ${ }^{29}$ the PFS difference was 4.5 months for those treated with afatinib versus 1.0 month for those who received placebo, suggesting that afatinib may have its greatest impact in subgroups of patients with EGFR mutations. $^{61}$

LUX-Lung 2 was a phase II open-label, single-arm trial in 129 patients with stage IIIb/IV adenocarcinoma of the lung with confirmed EGFR-activating mutations. ${ }^{55}$ Sixty-one patients received afatinib as first-line treatment, and 68 patients received afatinib as second-line treatment 


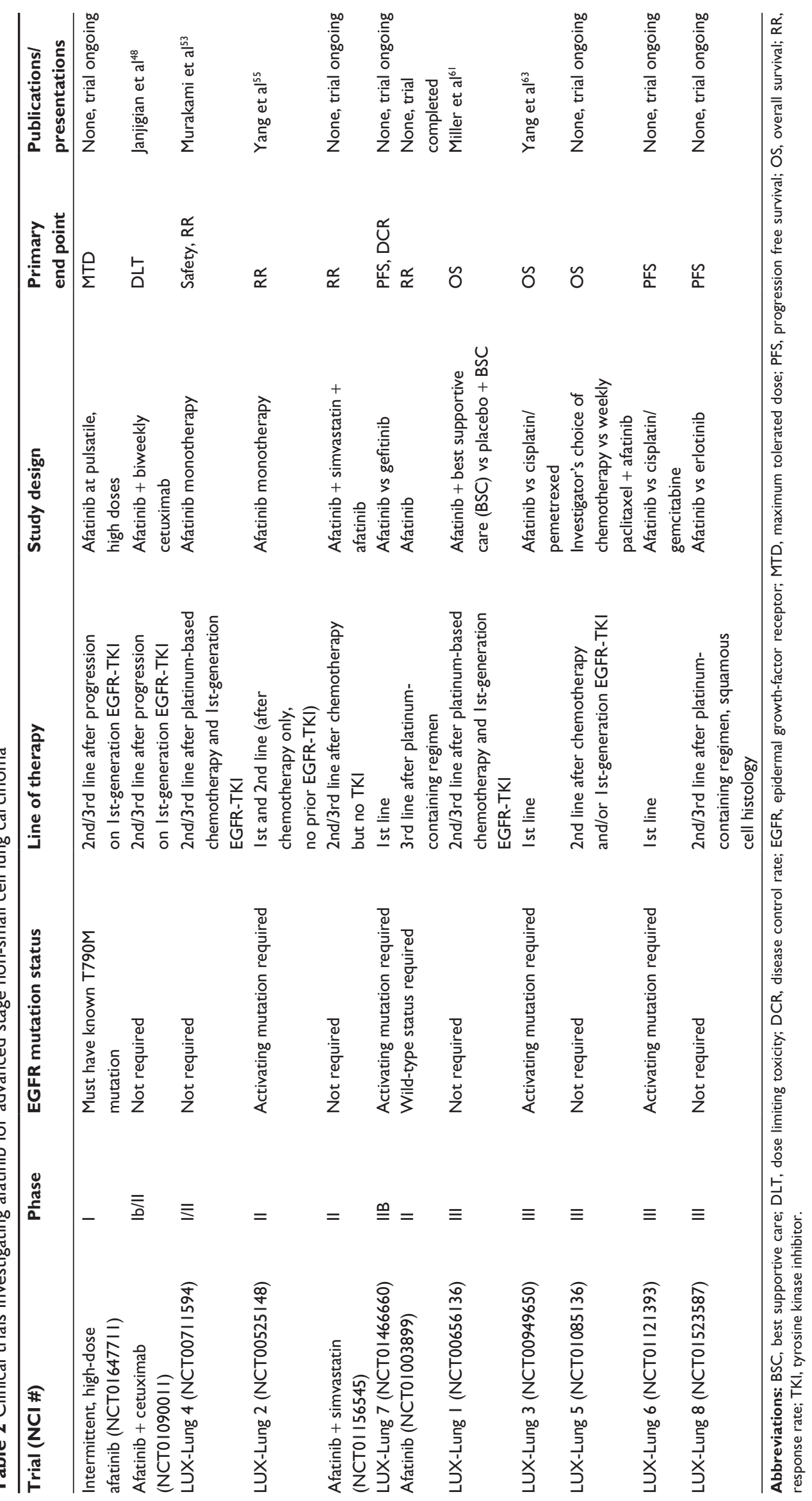


after progressing following cytotoxic therapy. No patients had been exposed to prior EGFR-TKIs. The patients continued on afatinib $50 \mathrm{mg} /$ day (later decreased to $40 \mathrm{mg} /$ day for improved tolerability) until progression or undue toxicity.

At median follow-up of 22 months, planned analysis was performed. The primary end point, overall RR, was $61 \%$. Notably, $66 \%$ of those with exon 19 deletion or exon $21 \mathrm{~L} 858 \mathrm{R}$ mutations had a response to treatment, while only $39 \%$ of those with less common EGFR mutations did. The vast majority $(87 \%)$ of responses occurred within 8 weeks. There was no difference in RR based on prior chemotherapy. The median response duration was 12.9 months by independent assessment and 14 months by investigator assessment. Median PFS was slightly shorter in the subset of patients with less common mutations, 10.1 months (95\% CI 8.12-13.80 months), and slightly longer in those for whom afatinib was first-line treatment. These results are similar to those seen in analogous trials of first-generation EGFR-TKIs. The median OS was 23.3 months (95\% CI 18.53-38.01 months) in those patients receiving afatinib in the second-line setting and was not reached for patients who received afatinib as first-line treatment.

The results of the LUX-Lung 3 trial were presented at the annual American Society of Clinical Oncology meeting in June 2012. In this phase III trial, 345 patients with EGFR mutation-positive advanced NSCLC were randomized to receive afatinib or cisplatin/pemetrexed as first-line therapy. After a median follow-up of 8 months, PFS in the afatinib group was 11.1 months compared to 6.9 months in the chemotherapy arm (HR 0.58, $P=0.0004)$. Among the 308 patients with the common mutations exon 19 deletion or exon 21 L858R mutation, the difference in PFS was even more striking: 13.6 months with afatinib compared to 6.9 months in the chemotherapy group (HR $0.47, P<0.0001$ ). OS data will be available in 2 years. ${ }^{62}$

Upcoming and ongoing trials of afatinib include additional single-agent afatinib trials in the LUX-Lung series (Table 2) as well as a phase II trial of afatinib in the third-line treatment of EGFR wild-type advanced NSCLC ${ }^{63}$ and a phase Ib/II combination trial with afatinib and cetuximab after progression on a first-generation EGFR-TKI. Thus far, results have been promising in this latter trial, with disease control reported in the first 26 patients, including $36 \%$ with partial responses and four out of 13 responses in T790M-mutated patients. ${ }^{64}$

\section{Patient-focused perspectives}

Despite the frequency of side effects, patients report improved quality of life with afatinib treatment. ${ }^{59,61}$ When compared with placebo, patients with advanced, non-small cell lung cancer treated with afatinib (vs placebo) reported statistically significant improvement in cough (46\% vs $25 \%)$, dyspnea (51\% vs 36\%), and pain (50\% vs 32\%). ${ }^{61}$ Preliminary results from LUX-Lung 3 comparing afatinib versus cisplatin and pemetrexed as first-line treatment in patients with advanced lung adenocarcinoma demonstrate a statistically significant delay in onset of cough (HR 0.60) and dyspnea (HR 0.68) with afatinib treatment. ${ }^{62}$ LUX-Lung 3 also demonstrated improvement in health-related quality of life with afatinib compared to chemotherapy. A higher proportion of patients treated with afatinib (vs placebo) had a 10-point or more improvement in cough (67\% vs 60\%), dyspnea (64\% vs $50 \%$ ), and pain (59\% vs $48 \%$ ) when analyzed using the European Organisation for Research and Treatment of Cancer (EORTC) standardized quality-of-life questionnaire for lung cancer (QLQ-LC13). ${ }^{65}$ Quality of life and its determinants were evaluated using the EORTC QLQ-C30 questionnaire, and patients treated with afatinib experienced improvements in their overall well-being and physical, cognitive, and role functioning compared with chemotherapy $(P<0.05){ }^{65}$

\section{Conclusion}

The first-generation reversible EGFR-TKIs erlotinib and gefitinib have yielded impressive clinical benefits for patients with EGFR-mutated NSCLC. Unfortunately, these benefits are transient due to the mutability of tumor-cell genomes and the resultant resistance that develops to these agents. Thus, additional treatments that can overcome or prevent resistance are needed. Just as erlotinib and gefitinib are most effective in patients with EGFR-activating mutations, irreversible EGFR-TKIs such as afatinib likely have their own particular niche. At the present time, afatinib's role is not yet defined. It may be best utilized as a second- or third-line TKI in patients with the most common resistance mutations. Or it may simply prove to be a third EGFR-TKI option for patients with EGFR-activating mutations.

At a minimum, afatinib appears comparable to current first-generation EGFR-TKI options. In the first-line treatment of patients with common activating mutations, phase III studies show PFS of 9.7-13.1 months with erlotinib, ${ }^{22,23}$ 9.2-9.4 months with gefitinib, ${ }^{25,27}$ and 11.1 months with afatinib. ${ }^{62}$ Admittedly, cross-trial comparisons do not take into account different patient characteristics such as EGFR mutation status, thus a head-to-head comparison would be prudent. In the meantime, continued efforts to determine the molecular subtype of patients who will most benefit from afatinib are ongoing. 


\section{Disclosure}

The authors report no conflicts of interest in this work.

\section{References}

1. National Comprehensive Cancer Network. NCCN Clinical Practice Guidelines in Oncology: Non-Small Cell Lung Cancer. 2012. Available from: http://www.nccn.org/professionals/physician_gls/f_guidelines. asp. Accessed October 14, 2012.

2. Doll R, Gray R, Hafner B, Peto R. Mortality in relation to smoking: 22 years' observations on female British doctors. BMJ. 1980;280(6219): 967-971.

3. Janerich DT, Thompson WD, Varela LR, et al. Lung cancer and exposure to tobacco smoke in the household. $N$ Engl J Med. 1990;323(10): 632-636.

4. Turner MC, Krewski D, Chen Y, Pope CA 3rd, Gapstur S, Thun MJ. Radon and lung cancer in the American Cancer Society cohort. Cancer Epidemiol Biomarkers Prev. 2011;20(3):438-448.

5. Heintz NH, Janssen-Heininger YM, Mossman BT. Asbestos, lung cancers, and mesotheliomas: from molecular approaches to targeting tumor survival pathways. Am J Respir Cell Mol Biol. 2010;42(2):133-139.

6. Sandler A, Gray R, Perry MC, et al. Paclitaxel-carboplatin alone or with bevacizumab for non-small-cell lung cancer. $N$ Engl $J$ Med. 2006;355(24):2542-2550.

7. Reid A, Vidal L, Shaw H, de Bono J. Dual inhibition of ErbB1 (EGFR/ HER1) and ErbB2 (HER2/neu). Eur J Cancer. 2007;43(3):481-489.

8. Herbst RS, Heymach JV, Lippman SM. Lung cancer. $N$ Engl J Med. 2008;359(13):1367-1380.

9. Spicer JF, Rudman SM. EGFR inhibitors in non-small cell lung cancer (NSCLC): the emerging role of the dual irreversible EGFR/ HER2 inhibitor BIBW 2992. Target Oncol. 2010;5(4):245-255.

10. Gazdar AF. Activating and resistance mutations of EGFR in non-smallcell lung cancer: role in clinical response to EGFR tyrosine kinase inhibitors. Oncogene. 2009;28 Suppl 1:S24-S31.

11. Ray M, Salgia R, Vokes EE. The role of EGFR inhibition in the treatment of non-small cell lung cancer. Oncologist. 2009;14(11): 1116-1130.

12. Murray S, Dahabreh IJ, Linardou H, Manoloukos M, Bafaloukos D, Kosmidis P. Somatic mutations of the tyrosine kinase domain of epidermal growth factor receptor and tyrosine kinase inhibitor response to TKIs in non-small cell lung cancer: an analytical database. J Thorac Oncol. 2008;3(8):832-839.

13. Riely GJ, Politi KA, Miller VA, Pao W. Update on epidermal growth factor receptor mutations in non-small cell lung cancer. Clin Cancer Res. 2006;12(24):7232-7241.

14. Engelman JA, Janne PA. Mechanisms of acquired resistance to epidermal growth factor receptor tyrosine kinase inhibitors in non-small cell lung cancer. Clin Cancer Res. 2008;14(10):2895-2899.

15. Sharma SV, Bell DW, Settleman J, Haber DA. Epidermal growth factor receptor mutations in lung cancer. Nat Rev Cancer. 2007;7(3): 169-181.

16. Shepherd FA, Rodrigues Pereira J, Ciuleanu T, et al. Erlotinib in previously treated non-small-cell lung cancer. N Engl J Med. 2005;353(2): 123-132.

17. Jackman DM, Miller VA, Cioffredi LA, et al. Impact of epidermal growth factor receptor and KRAS mutations on clinical outcomes in previously untreated non-small cell lung cancer patients: results of an online tumor registry of clinical trials. Clin Cancer Res. 2009;15(16): $5267-5273$.

18. Rosell R, Moran T, Queralt C, et al. Screening for epidermal growth factor receptor mutations in lung cancer. N Engl J Med. 2009;361(10): 958-967.

19. Inoue A, Suzuki T, Fukuhara T, et al. Prospective phase II study of gefitinib for chemotherapy-naive patients with advanced non-smallcell lung cancer with epidermal growth factor receptor gene mutations. J Clin Oncol. 2006;24(21):3340-3346.
20. Janne PA, Wang X, Socinski MA, et al. Randomized phase II trial of erlotinib alone or with carboplatin and paclitaxel in patients who were never or light former smokers with advanced lung adenocarcinoma: CALGB 30406 trial. J Clin Oncol. 2012;30(17):2063-2069.

21. Jackman DM, Yeap BY, Sequist LV, et al. Exon 19 deletion mutations of epidermal growth factor receptor are associated with prolonged survival in non-small cell lung cancer patients treated with gefitinib or erlotinib. Clin Cancer Res. 2006;12(13):3908-3914.

22. Rosell R, Carcereny E, Gervais R, et al. Erlotinib versus standard chemotherapy as first-line treatment for European patients with advanced EGFR mutation-positive non-small-cell lung cancer (EURTAC): a multicentre, open-label, randomised phase 3 trial. Lancet Oncol. 2012;13(3):239-246.

23. Zhou $\mathrm{C}, \mathrm{Wu} \mathrm{YL}$, Chen G, et al. Erlotinib versus chemotherapy as first-line treatment for patients with advanced EGFR mutationpositive non-small-cell lung cancer (OPTIMAL, CTONG-0802): a multicentre, open-label, randomised, phase 3 study. Lancet Oncol. 2011;12(8):735-742.

24. Gridelli C, De Marinis F, Di Maio M, Cortinovis D, Cappuzzo F, Mok T. Gefitinib as first-line treatment for patients with advanced nonsmall-cell lung cancer with activating epidermal growth factor receptor mutation: review of the evidence. Lung Cancer. 2011;71(3):249-257.

25. Mok TS, Wu YL, Thongprasert S, et al. Gefitinib or carboplatinpaclitaxel in pulmonary adenocarcinoma. $N$ Engl J Med. 2009;361(10): 947-957.

26. Maemondo M, Inoue A, Kobayashi K, et al. Gefitinib or chemotherapy for non-small-cell lung cancer with mutated EGFR. $N$ Engl J Med. 2010;362(25):2380-2388.

27. Mitsudomi T, Morita S, Yatabe Y, et al. Gefitinib versus cisplatin plus docetaxel in patients with non-small-cell lung cancer harbouring mutations of the epidermal growth factor receptor (WJTOG3405): an open label, randomised phase 3 trial. Lancet Oncol. 2010;11(2):121-128.

28. Paz-Ares L, Soulieres D, Melezinek I, et al. Clinical outcomes in nonsmall-cell lung cancer patients with EGFR mutations: pooled analysis. J Cell Mol Med. 2010;14(1-2):51-69.

29. Jackman D, Pao W, Riely GJ, et al. Clinical definition of acquired resistance to epidermal growth factor receptor tyrosine kinase inhibitors in non-small-cell lung cancer. J Clin Oncol. 2010;28(2):357-360.

30. Pao W, Miller VA, Politi KA, et al. Acquired resistance of lung adenocarcinomas to gefitinib or erlotinib is associated with a second mutation in the EGFR kinase domain. PLoS Med. 2005;2(3):e73.

31. Arcila ME, Oxnard GR, Nafa K, et al. Rebiopsy of lung cancer patients with acquired resistance to EGFR inhibitors and enhanced detection of the T790M mutation using a locked nucleic acid-based assay. Clin Cancer Res. 2011;17(5):1169-1180.

32. Sequist LV, Waltman BA, Dias-Santagata D, et al. Genotypic and histological evolution of lung cancers acquiring resistance to EGFR inhibitors. Sci Transl Med. 2011;3(75):75ra26.

33. Ou SH. Second-generation irreversible epidermal growth factor receptor (EGFR) tyrosine kinase inhibitors (TKIs): a better mousetrap? A review of the clinical evidence. Crit Rev Oncol Hematol. 2012;83(3): 407-421.

34. Balak MN, Gong Y, Riely GJ, et al. Novel D761Y and common secondary T790M mutations in epidermal growth factor receptor-mutant lung adenocarcinomas with acquired resistance to kinase inhibitors. Clin Cancer Res. 2006;12(21):6494-6501.

35. Bean J, Riely GJ, Balak M, et al. Acquired resistance to epidermal growth factor receptor kinase inhibitors associated with a novel T854A mutation in a patient with EGFR-mutant lung adenocarcinoma. Clin Cancer Res. 2008;14(22):7519-7525.

36. Costa DB, Halmos B, Kumar A, et al. BIM mediates EGFR tyrosine kinase inhibitor-induced apoptosis in lung cancers with oncogenic EGFR mutations. PLoS Med. 2007;4(10):1669-1679; discussion 1680.

37. Engelman JA, Zejnullahu K, Mitsudomi T, et al. MET amplification leads to gefitinib resistance in lung cancer by activating ERBB3 signaling. Science. 2007;316(5827):1039-1043. 
38. Suda K, Tomizawa K, Fujii M, et al. Epithelial to mesenchymal transition in an epidermal growth factor receptor-mutant lung cancer cell line with acquired resistance to erlotinib. J Thorac Oncol. 2011;6(7): 1152-1161.

39. Maheswaran S, Sequist LV, Nagrath S, et al. Detection of mutations in EGFR in circulating lung-cancer cells. $N$ Engl J Med. 2008;359(4): 366-377.

40. Rosell R, Molina MA, Costa C, et al. Pretreatment EGFR T790M mutation and BRCA1 mRNA expression in erlotinib-treated advanced non-small-cell lung cancer patients with EGFR mutations. Clin Cancer Res. 2011;17(5):1160-1168.

41. Su KY, Chen HY, Li KC, et al. Pretreatment epidermal growth factor receptor (EGFR) T790M mutation predicts shorter EGFR tyrosine kinase inhibitor response duration in patients with non-small-cell lung cancer. J Clin Oncol. 2012;30(4):433-440.

42. Riely GJ, Kris MG, Zhao B, et al. Prospective assessment of discontinuation and reinitiation of erlotinib or gefitinib in patients with acquired resistance to erlotinib or gefitinib followed by the addition of everolimus. Clin Cancer Res. 2007;13(17):5150-5155.

43. Costa DB, Nguyen KS, Cho BC, et al. Effects of erlotinib in EGFR mutated non-small cell lung cancers with resistance to gefitinib. Clin Cancer Res. 2008;14(21):7060-7067.

44. Chaft JE, Oxnard GR, Sima CS, Kris MG, Miller VA, Riely GJ. Disease flare after tyrosine kinase inhibitor discontinuation in patients with EGFR-mutant lung cancer and acquired resistance to erlotinib or gefitinib: implications for clinical trial design. Clin Cancer Res. 2011; 17(19):6298-6303.

45. Pietanza MC, Lynch TJ Jr, Lara PN Jr, et al. XL647 - a multitargeted tyrosine kinase inhibitor: results of a phase II study in subjects with non-small cell lung cancer who have progressed after responding to treatment with either gefitinib or erlotinib. J Thorac Oncol. 2012;7(1): 219-226.

46. Johnson ML, Riely GJ, Rizvi NA, et al. Phase II trial of dasatinib for patients with acquired resistance to treatment with the epidermal growth factor receptor tyrosine kinase inhibitors erlotinib or gefitinib. J Thorac Oncol. 2011;6(6):1128-1131.

47. Sequist LV, Besse B, Lynch TJ, et al. Neratinib, an irreversible panErbB receptor tyrosine kinase inhibitor: results of a phase II trial in patients with advanced non-small-cell lung cancer. J Clin Oncol. 2010;28(18):3076-3083.

48. Janjigian YY, Azzoli CG, Krug LM, et al. Phase I/II trial of cetuximab and erlotinib in patients with lung adenocarcinoma and acquired resistance to erlotinib. Clin Cancer Res. 2011;17(8):2521-2527.

49. Li D, Ambrogio L, Shimamura T, et al. BIBW2992, an irreversible EGFR/HER2 inhibitor highly effective in preclinical lung cancer models. Oncogene. 2008;27(34):4702-4711.

50. Yap TA, Vidal L, Adam J, et al. Phase I trial of the irreversible EGFR and HER2 kinase inhibitor BIBW 2992 in patients with advanced solid tumors. J Clin Oncol. 2010;28(25):3965-3972.

51. Metro G, Crino L. The LUX-Lung clinical trial program of afatinib for nonsmall-cell lung cancer. Expert Rev Anticancer Ther. 2011;11(5): 673-682.

52. Kwak EL, Sordella R, Bell DW, et al. Irreversible inhibitors of the EGF receptor may circumvent acquired resistance to gefitinib. Proc Natl Acad Sci U S A. 2005;102(21):7665-7670.
53. Murakami H, Tamura T, Takahashi T, et al. Phase I study of continuous afatinib (BIBW 2992) in patients with advanced non-small cell lung cancer after prior chemotherapy/erlotinib/gefitinib (LUX-Lung 4). Cancer Chemother Pharmacol. 2012;69(4):891-899.

54. Agus DB, Terlizzi E, Stopfer P, Amelsberg A, Gordon MS. A phase I dose escalation study of BIBW 2992, an irreversible dual EGFR/HER2 receptor tyrosine kinase inhibitor, in a continuous schedule in patients with advanced solid tumours. J Clin Oncol. 2006;24(18):97S-97S.

55. Yang JC, Shih JY, Su WC, et al. Afatinib for patients with lung adenocarcinoma and epidermal growth factor receptor mutations (LUX-Lung 2): a phase 2 trial. Lancet Oncol. 2012;13(5):539-548.

56. Schuler M, Awada A, Harter P, et al. A phase II trial to assess efficacy and safety of afatinib in extensively pretreated patients with HER2-negative metastatic breast cancer. Breast Cancer Res Treat 2012;134(3):1149-1159.

57. Eskens FA, Mom CH, Planting AS, et al. A phase I dose escalation study of BIBW 2992, an irreversible dual inhibitor of epidermal growth factor receptor 1 (EGFR) and 2 (HER2) tyrosine kinase in a 2-week on, 2-week off schedule in patients with advanced solid tumours. $\mathrm{Br} J$ Cancer. 2008;98(1):80-85.

58. Cohen MH, Johnson JR, Chen YF, Sridhara R, Pazdur R. FDA drug approval summary: erlotinib (Tarceva) tablets. Oncologist. 2005;10(7):461-466.

59. Lin NU, Winer EP, Wheatley D, et al. A phase II study of afatinib (BIBW 2992), an irreversible ErbB family blocker, in patients with HER2-positive metastatic breast cancer progressing after trastuzumab. Breast Cancer Res Treat. 2012;133(3):1057-1065.

60. Barber NA, Ganti AK. Pulmonary toxicities from targeted therapies: a review. Target Oncol. 2011;6(4):235-243.

61. Miller VA, Hirsh V, Cadranel J, et al. Afatinib versus placebo for patients with advanced, metastatic non-small-cell lung cancer after failure of erlotinib, gefitinib, or both, and one or two lines of chemotherapy (LUXLung 1): a phase 2b/3 randomised trial. Lancet Oncol. 2012;13(5): $528-538$.

62. Yang CH, Schuler MH, Yamamoto N, et al. LUX-Lung 3: a randomized, open-label, phase III study of afatinib versus pemetrexed and cisplatin as first-line treatment for patients with advanced adenocarcinoma of the lung harboring EGFR-activating mutations. J Clin Oncol. 2012;30 Suppl:LBA7500.

63. Boehringer Ingelheim Pharmaceuticals. A phase II trail of afatinib (BIBW 2992) in third-line treatment for patients with stage IIIB/IV adenocarcinoma of the lung harbouring wild-type epidermal growth factor receptor (EGFR). In: ClinicalTrials.gov [website on the Internet]. Bethesda, MD: US National Library of Medicine; 2012 [updated April 13, 2012]. Available from: http://clinicaltrials.gov/ ct2/show/NCT01003899 NLM identifier: NCT01003899. Accessed October 14, 2012.

64. Janjigian YY GH, Horn L, Smit EF, et al. Activity and tolerability of afatinib (BIBW 2992) and cetuximab in NSCLC patients with acquired resistance to erlotinib and gefitinib. J Clin Oncol. 2011;29 Suppl: 7525.

65. Sequist LV, Schuler n, Yamamoto M, et al. LUX-Lung 3: Symptom and health-related quality of life results from a randomized phase III study in 1st-line advanced NSCLC patients harbouring EGFR mutations. 37th ESMO Congress; September 28-October 2, 2012; Vienna, Austria.
OncoTargets and Therapy

\section{Publish your work in this journal}

OncoTargets and Therapy is an international, peer-reviewed, open access journal focusing on the pathological basis of all cancers, potential targets for therapy and treatment protocols employed to improve the management of cancer patients. The journal also focuses on the impact of management programs and new therapeutic agents and protocols on

\section{Dovepress}

patient perspectives such as quality of life, adherence and satisfaction The manuscript management system is completely online and includes a very quick and fair peer-review system, which is all easy to use. Visit http://www.dovepress.com/testimonials.php to read real quotes from published authors. 